\title{
DIVERSIFYING POLICE RECRUITMENT? THE DEPLOYMENT OF POLICE COMMUNITY SUPPORT OFFICERS IN LONDON
}

\author{
LES JOHNSTON, Professor of Criminology, University of Portsmouth
}

\begin{abstract}
As part of a drive to extend 'the police family', the Police Reform Act (2002) introduced Police Community Support Officers (PCSOs) into the police service. Though the main function of PCSOs is to enhance public reassurance by providing visible uniformed patrol, it is also anticipated that PCSO recruitment - more demographically diverse than regular recruitment - will make the police more genuinely representative of the diverse communities they police. Drawing upon research carried out in the Metropolitan Police Service (MPS), this paper considers how far quantitative targets in respect of diverse recruitment are being met; outlines some of the organisational problems impacting on diversity; and notes the limitations of greater 'representativeness'.
\end{abstract}

Key words: Police Community Support Officers; Diversity; Ethnic representativeness. 


\section{Introduction}

As part of its drive to extend 'the police family', the Police Reform Act (2002) introduced Police Community Support Officers (PCS0s) into the service. PCSOs are uniformed staff employed by the police authority; they work under the direction and control of the chief officer; and they possess certain limited powers (such as the power to issue fixed penalty notices for certain offences and the power to confiscate alcohol under specified conditions). Currently, there are about 4,000 PCSOs operating in England and Wales, 1,200 of whom work for the Metropolitan Police Service (MPS). However, this number will increase substantially in the near future with the recent White Paper having pledged support for the recruitment of a further 20,000 PCSOs over the next three years (Home Office 2004a; see also HM Government 2004). The main function of PCSOs is to enhance public reassurance and contribute to the reduction of low level crime and disorder by undertaking visible street patrols (Home Office 2004a, p. 165). They first became operational in September 2002 when the MPS deployed 'Security PCSOs' in Westminster to carry out anti-terrorist patrols. During 2002-3 ‘Community PCSOs’, charged with providing visible patrol in communities and 'Transport PCSOs', charged with policing the city’s transport routes, were introduced on a London-wide basis. This paper draws upon evaluative research into PCSOs carried out in two MPS boroughs (Westminster and Camden) between October 2002 and December $2003 .{ }^{1}$

Though the main function of PCSOs is to enhance public reassurance, their recruitment is also linked to a second agenda. As a recent Home Office discussion paper stated: 'our direction of travel is clear - towards an engaged, responsive, accountable, truly representative local police service ...' (Home Office 2003, p. 2, italics added). The 
issue of representativeness has been a difficult one for the police service and has posed particular problems for the MPS. By 2009, police organisations in England and Wales are expected to have an ethnic composition proportional to that of the local population they serve (Home Office 1999). With a quarter of London's population defined as minority ethnic, the MPS will be particularly hard-pushed to reach this target. ${ }^{2}$ In 1992, only 3.3\% of its officers were from visible minority ethnic groups. Though the proportion had risen to $4.9 \%$ by 2002, as Rowe (2004) points out, based on these figures the MPS would still need to recruit a further 5,661 minority ethnic officers in order to meet the 2009 target. Despite continued improvement - by early 2004 the proportion of visible ethnic minority officers in the MPS stood at 6.3\% (MPS 2004b) - such a target is likely to be problematic given the organisation's recurrent failure to recruit and retain officers from this pool.

The recruitment of PCSOs in the MPS was, thus, driven by two parallel agendas: to enhance public reassurance through the provision of visible, uniformed patrol; and to help diversify MPS recruitment thus making the organisation more representative of the community it polices. ${ }^{3}$ This paper is concerned exclusively with the second of these issues. While our main focus is on ethnic diversity, brief reference will also be made to gender and age aspects of PCSO recruitment. The paper is divided into three parts. The first analyses PCSO application and recruitment data and considers the extent to which quantitative goals regarding diversity are being realised. The second examines a number of organisational issues relating to diversification. The third makes some brief comments on the limits and possibilities of representativeness.

An analysis of applicants and recruits 
In its Priorities for Excellence 2003/4 (MPS 2004a) the MPS expressed its desire to achieve the following recruitment targets:

29\% women PCSO recruits as a percentage of all PCSO recruits $26 \%$ women PCSOs as a percentage of all PCSOs 25\% minority ethnic PCSO recruits as a percentage of all PCSO recruits $25 \%$ minority ethnic PCSO recruits as a percentage of all PCSOs

In order to gauge how far these objectives were being met an analysis was undertaken of 2025 PCSO applications submitted to and processed by the MPS during the year $1^{\text {st }}$ April 2002 to $31^{\text {st }}$ March 2003. Two-thirds of applications (66\%) came from males and around one quarter (26\%) from females. Though, the MPS has no specified targets with respect to the age profile of applicants, it is clear that many individuals are applying to become PCSOs later in their working life than is the case with applications to the regular police. In our sample the median age for applicants was around 34 years of age with about a quarter of applications coming from people aged over 39 years of age.

Table 1 summarises applications according to ethnicity. Complication was added to this part of the analysis by the fact that during the course of the year the MPS changed the coding system used by staff at Hendon to identify ethnic background. Originally the system employed a six-fold classification based broadly upon the outward appearance ('IC Code') of the individual. Of the 2025 applicants contained in our sample, 1040 were classified on this basis. The remaining 985 applicants were categorised according to a more complex classification system, the aim of which is to capture ethnic diversity more effectively. Table 1 summarises the ethnic distribution of applicants according to these two systems 
Insert TABLE 1 about here

When the two categorizations are combined it can be seen that around $44 \%$ of applicants are 'White’ (i.e. 'White N. and S. European', ‘White British', ‘White Irish’ or 'White Other') and that around 34\% of applicants are from minority ethnic groups. A further $22 \%$ chose to leave their ethnic designation 'blank' on the application form ${ }^{4}$. Removing these 450 'blanks' from the table on the grounds that we cannot know their ethnicity, leaves us with 1575 applicants, 56\% of whom may be designated 'White' and 44\% of whom may be designated members of minority ethnic groups.

Of the 2025 applicants contained in the sample 430 (21\%) were eventually recruited as PCSOs of whom 313 (73\%) were male, 111 (26\%) female and 6 (1\%) of unknown gender ('blanks'). The \% likelihood of recruitment among male applicants was slightly higher (at 23\%) than that for female applicants (at 21\%). The highest levels of recruitment by age were found amongst the 20-24 and 30-34 age groups (both 19\%) though, the greatest likelihood of recruitment was found amongst those aged 50-4 (26\%) and $55+(31 \%)$.

Table 2 reviews recruitment by ethnic category. According to the table (see Column C) around 57\% of recruits may be defined as 'White' ('White N. and S. European', 'White British', 'White Irish’ or 'White Other') and around 32\% may be defined as members of minority ethnic communities. A further $10 \%$ of recruits chose to leave their ethnic designation 'blank' when filling in the application form. Removing these 41 'blanks' from the table, on the grounds that we cannot know their ethnicity, 
leaves us with 386 recruits, $65 \%$ of whom may be designated 'White' and 35\% of whom may be designated members of minority ethnic groups.

Insert TABLE 2 about here

As regards likelihood of recruitment (see Column D), making percentage comparisons between the groups in the revised ethnic classification is clearly inappropriate since the number contained within most groups is quite small. However, some percentage comparison is possible within the original ('IC Code'-based) classification where the numbers are larger. Here it would seem that applicants from the White (N. European) group have a somewhat higher chance of recruitment (at 34\%) than those from other sizeable IC groups (notably 'Blacks’ at 29\% and 'Asians' at 21\%). An alternative way of comparison (see Table 3) involves collapsing the sub-groups from both classifications into 'White' and 'Minority Ethnic' categories and calculating their overall likelihood of recruitment.

Insert TABLE 3 about here

To sum up. The overall likelihood of recruitment across the entire sample stands at $21 \%$. 'White' applicants (with a likelihood of 28\%) have a greater likelihood of being recruited than 'Minority Ethnic' applicants (with a likelihood of 20\%). Within the category of 'White' applicants, those from the IC1 group (with a likelihood of 34\%) have the greatest chance of all of being recruited.

A final point should be noted in respect of Table 2. While the likelihood of recruitment across the whole sample stood at 21\%, those processed under the earlier ('IC 
Code'-based) categorisation were revealed to have a much higher chance of recruitment (at 29\% - see Table 2 'Sub Total 1') than those recruited under the system that replaced it (at 13\% - see Table 2 'Sub Total 2'). Indeed, the recruitment chances of both 'White' and 'Minority Ethnic' candidates applying under the later system were around half of the chances of their counterparts applying under the earlier one. ${ }^{5}$ Though this disparity might reflect some decline in the quality of applicants over the period, it is much more likely to be the product of organisational factors affecting recruitment. It is to a consideration of these and related issues that the following section is addressed. ${ }^{6}$

\section{Organisational Factors and Diversity}

The above analysis indicates that the PCSO recruitment and selection process is proving successful in attracting groups currently underrepresented in the Metropolitan Police Service. In particular, our evidence would suggest that the target for minority ethnic recruitment (25\%) as outlined in Priorities for Excellence is being surpassed (with a figure of $35 \%$ in the sample) while the target for female recruitment (29\%) has almost been met (with a figure of $26 \%$ in the sample). However, while numerical targets are undoubtedly important, the goals of diversity and representativeness involve more than mere quantitative considerations. This section considers some of the organisational issues that lie behind the quantitative data outlined above.

In order to place these organisational issues in context three factors should be taken into account. The first concerns the motivation for becoming a PCSO. At an early stage of the research a workplace survey, examining attitudes towards the PCSO initiative, was administered to police, police staff and PCSOs at Charing Cross and 
Belgravia police stations, the two Westminster locations from which PCSOs were first deployed. When asked the question 'What was your main reason for wanting to become a PCSO at the time you joined'? a substantial proportion of PCSO respondents (50\% at Belgravia and $70 \%$ at Charing Cross) answered 'as a stepping stone to the regular police'. Semi-structured interviews carried out later revealed that many PCSOs saw entry as a means of 'testing the water' prior to applying to become a regular officer. This was no less true for minority ethnic PCSOs than for their white counterparts. Thus, a comment from a black PCSO - 'I read about PCSOs in the newspaper. I wanted to have a look at the police service and see if I liked the job’. (Male Black African PCSO aged 31) - could just as easily have been made by a white colleague. However, for many minority ethnic PCSOs, 'testing the water' involved more than simply 'checking over the job'. An Asian PCSO made it clear that, for him, one of the issues to be 'tested' was the potential for racism and discrimination within the organisation:

I've always been interested in joining the police and when PCSOs were first advertised, I thought that would be an opportunity to have a look at the job ... I was aware ... that there was racism and discrimination in the police service and I wondered how it would be for me being a PCSO ... I think there is some racism and discrimination but it is minimal and it is not something that is going to be a problem to my work and me. (Male English-born Asian PCSO aged 24)

By offering a means of 'testing the water' the PCSO initiative has undoubtedly succeeded in attracting recruits from communities which, in the past, would have had nothing to do with the MPS. ${ }^{7}$ For some minority ethnic PCSOs it also seems to have provided a new incentive for entry: one based upon the view that the 'normal' cultural obstacles to police recruitment are transformed.

We have recruited from communities (e.g. Bengalis in Tower Hamlets) who have never been attracted to the police. We did some consultancy ... some wanted to check [the job] out ... others felt there were cultural barriers to becoming a 
police officer that did not apply to becoming a PCSO (PCSO Programme Manager. Author's emphasis added)

A second factor to be taken into account involves implementation. An earlier evaluative study (Johnston et. al. 2004) to which the present analysis is related found that the single factor having the most negative impact on the organisation's capacity to recruit, integrate and manage PCSOs effectively was the speed with which the programme was implemented from autumn 2002 onwards There were several reasons for such speedy implementation: the fact that the MPS was being called upon to 'do something' in order to enhance security in the capital following the '9-11' terrorist attacks on the World Trade Centre; the fact that certain political and police opinion leaders were defining PCSOs as a key component in the developing agenda on police reform; and the fact that the Home Office decided to make significant funding for PCSOs available in summer 2002. The question of whether speedy implementation was desirable or avoidable is beyond the scope of this paper. What is indisputable is that problems emanated from it. These were particularly severe in Westminster due to the quantity of Security PCSOs allocated there. Within 4-5 months of the September launch, Charing Cross and Belgravia police stations had each received around 100 PCSOs. ${ }^{8}$ Predictably, organisational problems arose in the Borough due to an inability to plan for and absorb large numbers of new staff. These included a systemic failure to collect and collate management information data on PCSOs (e.g. with regard to sickness rates, appraisals, the quality of CRIMINT reports submitted or the extent to which their deployment released regular officers for operational duties), shortcomings in borough-based PCSO training (to accompany problems that already existed in the three week PCSO training programme 
provided centrally by the MPS) and, as the programme was rolled out to other Westminster stations, a repeated tendency for PCSOs to be 'dumped', at short notice, on the unprepared officers tasked to look after them.

A third factor to be noted concerns PCSO behavioural standards. Generally, standards of conduct were high. However, during 2003 a number of PCSOs - a high proportion of them coming from minority ethnic backgrounds - were the subject of disciplinary proceedings. Indeed, at one stage, a third of the minority ethnic PCSOs at Belgravia Police Station - around a dozen in number - were on disciplinary charges. We discuss this issue more fully below.

Let us now turn to organisational matters. Our contention is that while the MPS has undoubtedly achieved major success in tapping a new pool of recruits, a number of organisational problems impacted on the way the goals of representativeness and diversity were addressed during the first fifteen months of the implementation. Three such problems are considered here: those relating to the clarity with which PCSO roles, responsibilities and expectations were communicated within the MPS; those relating to the entry standards that were applied in the early stages of recruitment; and those relating to the institutional support - particularly the quantity and quality of supervision received by PCSOs. Though each of these problems affected PCSOs as a whole, it is likely that they had a particularly significant impact on minority ethnic recruits.

(i) clarity of communication regarding roles, responsibilities and expectations Due in large part to the scheme's rapid implementation, information about the roles and responsibilities of PCSOs - and about organisational expectations regarding PCSO 
conduct - were communicated badly. The following comment, describing the experience of a PCSO upon arriving at his police station, was typical of those reported to us: 'What were our aims? Nobody really knew. When we were posted on the teams it was a question of "Well, what do we do with them”'? (White female PCSO Charing Cross).

Some of these difficulties could be traced to shortcomings in the selection, recruitment and training processes - some of which were, themselves, linked to poor preparation arising from over-hasty implementation. One indication of this lack of preparation was the organisation's failure to design dedicated PCSO application forms, employing instead forms designed for applicants to the regular police. These forms had two shortcomings. First, they had the potential to confuse applicants about the distinctiveness of the PCSO role relative to the police role. Second, they failed to collect information about the skills and experiences of applicants, many of whom - because of their age, gender and ethnic diversity - could bring new capacities to the organisation.

Another factor was that the three-week MPS training programme was relatively poor at inculcating the values, attitudes and standards of conduct appropriate to a disciplined, uniformed, organisation. As a result, a small minority of PCSOs did not so much lack discipline as fail to understand how a disciplined organisation such as the police works. Soon after the commencement of the research police officers and PCSOs whom we were interviewing began to relate disciplinary problems to us. At first, we took these with 'a pinch of salt' - the product of disgruntled police officers complaining about the latest disruption to the status quo. However, it soon became apparent that a small minority of PCSOs were turning in late for shifts, failing to report sick, failing to wear the proper uniform, complaining about beat assignments and the like. On occasions, when 
carrying out patrol observations, we saw incidents of low level misconduct, such as PCSOs taking unauthorized coffee breaks. Once we witnessed a lengthy argument in a Camden police station between two minority ethnic PCSOs after one refused to go out on patrol with the other. Two and-a-half hours later, with no solution having been found, they were placed at each end of the front counter. They remained working there for a week while the matter was resolved. The following comment is particularly germane in regard to these behavioural issues:

PCSOs [did not] not know what was expected of them ... I think that was one of the major issues around recruitment - to find out long before they do training whether they know what was expected. Did they know about unsocial hours? Did they [Security PCSOs] know about the mind-numbing roles they were expected to carry out? What level of integrity and ethics was expected of them? (Member Black Police Association)

Though such difficulties were, by no means, associated only with minority ethnic PCSOs (Bellos 2003), the problems that some of them faced - newly recruited to an organisation unfamiliar with the difficulties of processing and integrating large numbers of ethnically diverse personnel - were probably greater than for their white counterparts.

(ii) entry standards for recruitment

A second issue concerns whether, in a context of rapid implementation, organisational demands to admit large numbers of PCSOs led to a lowering of entry standards during the early stages of recruitment. Our previous discussion of the quantitative evidence (see above and Footnote 4) seems to suggest that this is the case with the chances of both white and minority ethnic applicants at the initial (IC-based) stage of recruitment having been twice what they were at the later stage. Certainly, the view that entry standards were, initially, lowered was widely held amongst police officers involved in the process. 
One referred to a 'positive policy of recruitment' having been applied, while another spoke rather euphemistically about 'parameters of acceptance that could not easily be breached'. A third gave a more nuanced explanation:

Yes, I think early on there was some pressure ... Nobody has ever said 'we are going to lower standards here'. What happens is that people sort of internalise the assumption, so they do what they think the system wants them to do (Member PCSO Project Team).

Particular controversy surrounds the issue of ethnic minority recruitment. One interviewee said

In three different places [police stations where PCSOs had been deployed] ethnic minority PCSOs said they were told [at recruitment/selection interviews] that as long as they could walk and talk they would get the job (Member Black Police Association)

Of course, the fact that such advice and comment was given to minority ethnic PCSOs does not preclude it also having been given to white ones. Bellos's (2003) report on the circumstances surrounding the glut of disciplinary cases against minority ethnic PCSOs found 'no evidence ... that Black PCSOs had been recruited only because of their skin colour' (Bellos 2003. Executive Summary 2.4. Emphasis added). Indeed, our own quantitative data offers tentative support to Bellos’s view insofar as all applicants whether white or minority ethnic - enjoyed elevated levels of success during the earlier stages of recruitment.

On the other hand, Bellos's view is different from - though, given the only in the previous quote, by no means incompatible with - the Black Police Association's position. The BPA claims that 'positive discrimination' was applied during the early stages of the recruitment and selection process. According to this view, faced with demands for the recruitment of large numbers of minority ethnic PCSOs, the MPS first appointed a 
number who were ill-suited to the job. Having done so, it then failed to provide the institutional support that might have helped to bring them up to standard. Finally, when their behaviour did - as, inevitably, it would - fall short of the required standard, the organisation subjected them to discipline.

(iii) lack of institutional support

The shortcomings of the initial recruitment and selection process were certainly compounded by the organisation's failure to provide sufficient and appropriate institutional support to PCSOs. In the case of training, for example, the original intention had been that a borough-based course would supplement the initial three-week one. However, an internal MPS survey administered in Belgravia more than a year after the first PCSOs were deployed, while confirming that a substantial majority (90\%) had received further training, noted that it appeared 'to have been informal and unstructured'. Our interviews with supervisors in Westminster confirmed the 'informal' nature of such borough training and, in practice, much of the responsibility for borough-based training fell on to the reliefs.

Problems also arose in respect of supervision. In Camden, a decision had been made that PCSOs should be attached to Sector Teams and allocated a dedicated supervising sergeant. However, in Westminster, the repeated influx of large numbers of PCSOs made this impossible. There, because of a serious lack of available sergeants, supervision of PCSOs was minimal, much of it being delegated to Acting Sergeants, many of whom had only just completed their time as probationer constables. This was not a short term problem. The same internal survey found that three-quarters of PCSOs in 
Belgravia claimed never to have patrolled with a supervisor and around half claimed the level of supervision to have been 'poor'.

Though lack of adequate institutional support impacted on all PCSOs, whether white or minority ethnic, particular issues arose in respect of the latter. A moment ago we referred to the BPA's claim that some minority ethnic PCSOs had, as a result of 'positive discrimination', been recruited to posts for which they were unsuited. One BPA interviewee went as far as to suggest that these minority ethnic recruits had been 'set up to fail'. Though we found no evidence to support this view of events, it is undoubtedly true that some minority ethnic PCSOs were, sometimes, ineffective due to their failure to meet the capacities demanded of the role. Take, for instance, the matter of communication. One of the requirements for PCSOs is the ability to communicate clearly, in written and oral English, to colleagues and members of the public. A concern expressed to us by police officers in Westminster was the inability of some PCSOs notably some of those whose first language was not English - to communicate clearly over the radio:

I understand that they want to increase the number of ethnic minority recruits in both the civil and police side but ... surely ... if he can't speak English you can't have him out there with a radio trying to help people then relaying the information to us ... [what] if he comes across somebody needing an ambulance - someone [who] has been stabbed or something? (White, male PC/CAD Operator Belgravia)

What is striking about this example is not merely that, contrary to the MPS's own role requirements, a small number of individuals who could not communicate effectively were appointed as PCSOs; but that, having appointed them, the organisation put no institutional support in place to remedy their shortcomings. Overall, the situation may be summarised as follows. Reduced entry standards during the initial stages of recruitment 
caused a small minority of PCSOs - both white and minority ethnic - to be recruited who were unsuited to the role. Inadequate support structures, including shortcomings in training and supervision, exacerbated this situation. Minority ethnic PCSOs were probably more disadvantaged than their white counterparts in this regard since, on the one hand, they had the greatest need for institutional support and, on the other hand, were more visible - and thus more easily isolated as 'problems'- within an organisation unused to integrating minority ethnic personnel. The result was the plethora of 'disciplinaries' referred to previously.

Conclusion: the limits and possibilities of representativeness While the first part of this paper has shown that the MPS is well on course to meet its quantitative targets in respect of diversity within PCSO recruitment, the second part has indicated that qualitative factors need also to be considered. As Bellos (2004) suggests, diversity should never be concerned merely with head counts but should also take into account the capacity of an organisation to change while preserving its core standards and principles. This paper has focused on three of the many issues that impact on such organisational capacity: those relating to the communication of information about the roles, responsibilities and behavioural expectations of PCSOs; those concerning entry standards and recruitment; and those relating to institutional support.

Whether the organisational problems discussed here have general significance or are specific to our research sites is open to question. Certainly, the problems experienced in Westminster - and within Westminster especially at Belgravia - were far greater than those experienced in Camden or by other boroughs in the MPS. On the other hand, 
problems regarding supervision, training, communication and institutional support were neither restricted to Westminster nor, indeed, are they peculiar to the MPS. In fact, the limited research on PCSOs outside London replicates a number of our findings. ${ }^{9}$

However, it is the issue of institutional support that is crucial if the MPS is to become not only more representative of, but also more sensitive to, the needs of the communities it polices. Rigorous recruitment practices, coupled with appropriate institutional support can do much to diversify the workforce and enhance the representativeness of the organisation. Representativeness, in turn, produces real advantages, enabling both the organisation and the community to benefit from the skills, life experiences and expertise of recruits from a widening social and demographic spectrum. However, neither representativeness nor diversity are a panacea and we should be mindful of their limits as well as their possibilities. We conclude by mentioning two noteworthy limitations. The first concerns minority ethnic PCSOs who aspire to become regular police officers. There is already evidence to suggest that they are doing less well than their white colleagues in the 'fast track' process that leads to police recruitment. The danger is that a particularly unbalanced form of two-tier policing might emerge over time in which a predominantly white, male, regular police service works alongside a body of PCSOs made up, disproportionately, of female and minority ethnic personnel. In this situation the MPS may need to maintain a 'balancing act'. On the one hand, it may want to provide some additional institutional support for minority ethnic PCSOs wishing to enter the regular police service. On the other hand, by so doing, it will not want to denigrate the crucial role that minority ethnic PCSOs wishing to remain in that role can play in the community - as incumbents of a role that makes them both more visible and 
more accessible to the public than are regular police officers. This will be a difficult, though vital, balance for the MPS to maintain.

The second concerns the practical limits of representativeness. Commentators in both Britain (Holdaway 1996) and North America (Sherman 1983) have drawn attention to the fact that black police officers are sometimes as likely to hold negative stereotypes about sections of the black community as are white ones. As the following illustration shows, this may be no less true for PCSOs:

The other day three youths were stopped by a PC and a PCSO and we knew one of them had drugs. The PCSO was black and immediately searched the black man and found the drugs. Later, the PC asked the PCSO why he had searched the black man and not the two white youths. The PCSO said 'Well, you know it's always the black man who has the drugs’ (Police Inspector, Camden)

Thus, while enhanced representativeness is a desirable end in itself, it is important to recognise that the relationship between greater minority ethnic representation in the police service and more sensitive policing of ethnic minorities by the police service remains complex.

\section{REFERENCES}

Bellos, L. (2003) Report on Police Community Support Officers: Review of PCSO Scheme, Diversity Solutions (unpublished). 
Bellos, L. (2004) 'It means more than numbers', New Statesman, $17^{\text {th }}$ May.

Chatterton, M. and Rowlands, D. (2005) Community Support Officers: Report on Focus Group Discussions and Statistical Data, Police Federation of England and Wales, January 2005.

Crawford, A., Blackburn, S., Lister, S. and Shepherd, P. (2004) Patrolling With a Purpose: An Evaluation of Police Community Support Officers in Leeds and Bradford City Centres, Leeds: Centre for Criminal Justice Studies, University of Leeds.

HMIC [Her Majesty's Inspectorate of Constabulary] (2004) Modernising the Police Service: A Thematic Inspection of Workforce Modernisation - The Role, Management and Deployment of Police Staff in the Police Service of England and Wales, London: HMIC

HM Government (2004) Cutting Crime, Delivering Justice. A Strategic Plan for Criminal Justice 2004-08, Cm 6288, London: HMSO.

Holdaway, S. (1996) The Racialisation of British Policing, Basingstoke: Macmillan.

Home Office (1999) Dismantling Barriers to Reflect the Community We Serve. The Recruitment, Retention and Progression of Ethnic Minority Officers, London: Home Office.

Home Office (2003) Policing: Building Safer Communities Together, London: Home Office.

Home Office (2004a) Building Communities, Beating Crime: A Better Police Service for the $21^{\text {st }}$ Century, Cm 6360, London: HMSO.

Home Office (2004b) National Evaluation of Community Support Officers - Interim Report, December 2004.

Johnston, L., Donaldson, R. and Jones, D. (2004) Evaluation of the Deployment of Police Community Support Officers in the Metropolitan Police Service, Final Report, University of Portsmouth, unpublished.

[MPS] Metropolitan Police Service (2001) Metropolitan Special Constabulary. Report $11,19^{\text {th }}$ April 2001, http://www.mpa.gov.uk/committees/mpa/2001/010419/11.htm accessed 14th April 2005

[MPS] Metropolitan Police Service (2004a) Budget and Equalities Submission 2004-5 www.mpa.gov.uk/downloads/eodb-031204-11-appendix02.pdf accessed 29 ${ }^{\text {th }}$ July 2004. 
[MPS] Metropolitan Police Service (2004b) Metropolitan Police Service Management Board. Minutes of a meeting held at Lewisham Police Station, $2^{\text {nd }}$ March 2004 www.met.police.uk/foi/pdfs/minutes/MB_Minutes_2_March_2004.pdf accessed 12th August 2004

[MPS] Metropolitan Police Service (2004c) Review of the Metropolitan Police Special Constabulary, Report 13, $28^{\text {th }}$ October 2004, http://www.mpa.gov.uk/committees/mpa/2004/041028/13.htm?qs=1\&qu=Special+Const ables \&nh=1\&sc $=1 \& \mathrm{dr}=1 \& \mathrm{ar}=\& \mathrm{po}=\& \mathrm{fo}=\& \mathrm{lv}=\& \mathrm{pg}=1 \& \mathrm{hl}=1$ accessed $14^{\text {th }}$ April 2005

Rowe, M. (2004) Policing, Race and Racism, Cullompton: Willan.

Sherman, L. (1983) 'After the riots: police and minorities in the US 1970-1980', in Glazer, N. and Young, K. (eds.) Ethnic Pluralism and Public Policy, London:

Heinemann.

TABLE 1

No and \% of Applicants by Ethnic Categorisation

No $\%$

IC Classification 
IC1 White (N. European)

IC2 White (S. European)

IC3 Black

IC4 Asian

IC5 Chinese

IC6 Mixed

Blank

Sub Total 1
576

16

209

180

9

30

20

1040
28

1

10

9

$<1$

1

1

$>50$

New Classification

Any Other Group

$\begin{array}{rr}25 & 1 \\ 54 & 3 \\ 43 & 2 \\ 22 & 1 \\ 26 & 1 \\ 2 & <1 \\ 4 & <1 \\ 34 & 2 \\ 4 & <1 \\ 3 & <1 \\ 3 & <1 \\ 24 & 1 \\ 11 & 1 \\ 284 & 14 \\ 5 & <1 \\ 11 & 1 \\ 430 & 21\end{array}$

Black African

Bangladeshi

Black British

Black Caribbean

Chinese

Greek

Indian

Mixed White Black African

Any Other Mixed Background

Mixed White Black Caribbean

Pakistani

$<1$

Turkish

14

White British

$<1$

White Other

21

Sub Total 2

985

$>49$

Total

2025

100

The 'Blanks' referred to in this and later tables refer to applicants who did not fill in details about their gender, age or ethnicity on the application form. Around $8 \%$ of applicants failed to provide a gender or age identifier. A significantly greater proportion of applicants (22\%) gave no ethnic identifier. Though this raises important questions we were unable to investigate the issue further for reasons of data protection and confidentiality.

TABLE 2

Recruitment by Ethnic Category

A

No. of

Applicants
B

No. of

Recruits
C

$\%$ of

Recruits
D

\% Likelihood

Recruitment 
IC Classification

IC1 White (N. European) 576

IC2 White (S. European) 16

16

194

$45 \quad 34$

IC3 Black

180

IC4 Asian

9

IC5 Chinese

IC6 Mixed

30

Blank

20

15

Sub Total 1

1040

306

29

New Classification

Any Other Group 25

Black African 54

Bangladeshi 43

Black British 22

Black Caribbean 26

Chinese 2

Greek 4

Indian 34

Mixed White Black African 4

Any Other Mixed Background 3

Mixed White Black Caribbean 3

Pakistani

24

Turkish

11

White British

284

White Irish

5

White Other

11

Blank

430

985

124

$>28$

13

All

2025

430

100

21

TABLE 3 
\% Likelihood of Recruitment by Ethnic Category (Aggregated)

$\begin{array}{lll}\text { No of } & \text { No. of } & \text { \% Likelihood } \\ \text { Applicants } & \text { Recruits } & \text { of Recruitment }\end{array}$

$\begin{array}{lrrr}\text { 'White’ } & 892 & 250 & 28 \\ \text { 'Minority Ethnic' } & 683 & 136 & 20 \\ \text { 'Blanks' } & 450 & 44 & 10 \\ \text { All } & 2025 & 430 & 21\end{array}$

\section{NOTES}

${ }^{1}$ An earlier version of this paper was presented at the British Society of Criminology Conference, University of Portsmouth, 6-9 $9^{\text {th }}$ July, 2004. I am grateful to Dr. Roger Donaldson, Ms. Deborah Jones and Dr. Tom Williamson for their work on the original evaluation and for providing data used in this article. I am also grateful for the helpful advice of two anonymous referees who commented on an earlier version of the paper. The views expressed here are entirely the author's own. 

2A spokesperson for the MPS has recently declared the $25.9 \%$ minority ethnic target (Home Office 1999)
'unachievable'. The Commissioner of the MPS is one of several senior police figures to have called for
legislative change permitting 'affirmative action' policies to be introduced.

${ }^{3}$ Arguably, these agendas are not only parallel but overlapping given that representativeness might itself play a significant role in facilitating reassurance

${ }^{4}$ Provision of information regarding ethnic background is fundamental if applicants are to have their employment rights protected. Yet, it seems, failure to provide such information does not constitute a barrier to employment. This paradox is by no means peculiar to the police. The author discussed this issue with the Personnel Department of a large public sector organisation and was told that the problem was also commonplace there.

5 'White' applicants (IC Codes 1 and 2) had a 33\% likelihood of recruitment under the initial system in comparison to their counterparts under the later system ('White British', 'White Irish' and 'White Other') who had only a 17\% chance. 'Minority Ethnic’ applicants (IC Codes 3-6) had a 25\% likelihood of recruitment under the initial system in comparison to their counterparts under the later system (all 'nonwhite' groups) who had only a $12 \%$ chance.

${ }^{6}$ Our discussion of organisational factors is informed by evidence from several sources: a survey of police officers, police staff and PCSOs working at Belgravia and Charing Cross police stations administered in December 2002 and readminsiterd in September 2003; taped semi-structured interviews with police, police staff and PCSOs ( $\mathrm{N}=50)$ and with partner agencies, local stakeholders, community members and others $(\mathrm{N}=20)$; and ethnographic methods including observation within police stations, training observation and observation of PCSO patrols.

7 'Testing the water' has, of course, been a long-established motive for joining the Special Constabulary. Though it might have been anticipated that minority ethnic recruitment to the MPS Special Constabulary would have fallen as a result of potential applicants seeking positions as PCSOs this seems not to have happened. In April 2001 the MPS had a complement of 774 Special Constables, $17.3 \%$ of whom were from minority ethnic communities. By June 2003 that total had fallen to 681, of whom 15.6\% were minority ethnic. However, by October 2004 the figure had risen again to 765, 18.4\% of whom were minority ethnic (MPS 2001; MPS 2004c).

${ }^{8}$ At Camden, the second research site, managers had three months to plan for the eventual arrival of the 30 PCSOs allocated to the Borough

${ }^{9}$ Crawford et. al. (2004) note problems regarding training, supervision and 'learning by [hasty] implementation' in respect of PCSOs in West Yorkshire. Supervisory problems are identified both by Chatterton and Rowlands (2005) and in the recent Home Office's Interim Report ('The management of CSOs is likely to pose an ever-increasing challenge for forces, particularly with the additional 20,000 CSOs and wardens to be in place by 2008': Home Office 2004b, p. 9). The Inspectorate has confirmed our finding regarding the paucity of management data being compiled on PCSOs noting that 'the release of officers [through deployment of PCSOs] to operational duties in many forces is taken as given and is not adequately monitored' (HMIC 2004: 81). 